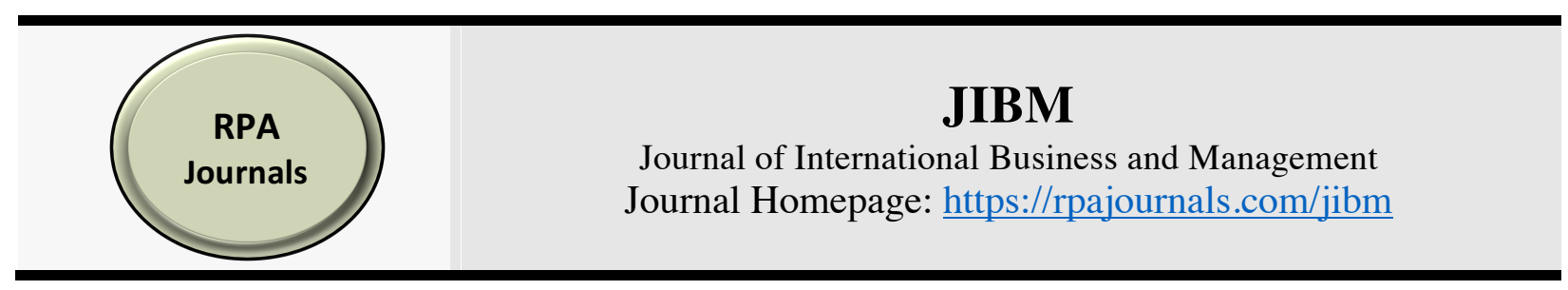

\title{
The Impact of Internationalization Processes on the Exploitation of Existing Markets: The Case of Italian Fashion SMEs
}

\author{
Angelo Arcuri \\ Horizons University, France
}

\begin{abstract}
To survive and prosper in the era of globalization, Italian fashion SMEs increasingly operate overseas, directly or through intermediaries. Expanding internationally helps these firms seize new business opportunities, but also confronts them with strategic and operational issues, challenging their ability to remain competitive in existing markets. Starting from these premises, an empirical study was conducted to assess the impact of internationalization processes on market exploitation in Italian fashion SMEs. The researcher analyzed a sample of 310 companies and adopted the explanatory sequential design, involving the use of quantitative and qualitative methods in two consecutive phases. According to the research results, most SMEs experienced a lower degree of responsiveness, higher costs and growing levels of organizational complexity during the first stages of internationalization, with detrimental effects on market exploitation.

Keywords: Internationalization, SMEs, Exploitation, Exploration, Operations, Italian Fashion
\end{abstract}

*Corresponding author: Angelo Arcuri; Email: arcuri.angelo81@gmail.com

DOI: https://doi.org/10.37227/JIBM-2021-01-129

\section{Introduction}

Engaging in an internationalization process requires SMEs to make significant efforts in terms of costs and organization. To gain market knowledge and connect with potential partners, SMEs tend to invest sizeable levels of resources during the first stage of their foreign expansion (Huynh et al., 2018). Also, they generally need to acquire and handle new assets and to revise their organizational model (Nummela and Loane, 2006). Hence, approaching new markets implies a number of changes affecting, to a greater or lesser extent, SMEs' operations and business results.

The impact of internationalization on firm performance has been extensively examined in the literature, both in relation to large companies and SMEs (Lee et al., 2010; Nguyen, 2016). However, there are no specific studies designed to ascertain whether and to what extent expanding overseas may negatively impact SMEs' ability to exploit their existing markets. Based on these assumptions, the present research paper analyzes the negative effects that an international expansion process may have on SMEs' exploitation activities from a practical standpoint. Learning more about the interaction between SMEs' exploitative dimension and internationalization is paramount in global business in light of the following considerations: first, focusing solely on exploration is insufficient, as firms need both to exploit their current markets and explore new destinations to succeed (Judge and Blocker, 2008; Zhang et al., 2015); second, SMEs are key economic players in terms of employment, contribution to GDP and innovation in all countries (Karadag, 2015); third, the internationalization of SMEs displays distinctive features requiring a specific analysis (Cerrato 
and Piva, 2010). To assess the effects of internationalization on SMEs' exploitation tasks, this study proposes to analyze if and to what degree three dimensions, namely organizational complexity, costs and responsiveness, change in response to an international growth process. Accordingly, the present paper is centered around the following research questions:

RQ1: What is the impact of internationalization on SMEs' organizational complexity?

RQ2: How are SMEs' costs related to an international expansion process?

RQ3: How does an international growth strategy influence SMEs' responsiveness?

Variations in each of the aforementioned variables may influence SMEs' operations and ability to meet the needs and expectations of their current customers. In particular, growing levels of organizational complexity give rise to coordination and control problems, because they entail additional tasks and alternative ways to design relationships (Tosi et al., 1994). Also, cost increases associated with internationalization processes may negatively affect SMEs' operations in existing markets, as exploration and exploitation compete for the organization's resources (March, 1991; Zhang et al., 2015). Lastly, a lower degree of responsiveness tends to result in decreased levels of customer satisfaction (Ye et al., 2017). Being fully aware of such implications may allow a company to maintain its current competitive advantages while seizing new business opportunities abroad. Hence, developing a better understanding of the connections existing between a firm's present business activities and internationalization may be a valuable aid to reaching a balance between exploration and exploitation, two essential elements for a company's survival and growth (Lavie et al., 2010). The present research work focuses on the Italian fashion industry, which mainly consists of SMEs with a well-established international presence and constitutes a pillar of the Italian economy, with eighty-thousand companies and a gross revenue of over $€ 70$ billion (Mediobanca, 2020).

\section{Literature Review}

This section summarizes and critically assesses the literature related to key aspects of SMEs' internationalization. It begins with the analysis of three key concepts, notably responsiveness, cost and organizational complexity, and their implications for international SMEs. The analysis of such dimensions introduces a topic of utmost importance for the purposes of this study: the models explaining the impact of an international venture on company performance. An overview of the Italian fashion industry completes the literature review, relating the research work to a specific business environment.

\section{Responsiveness, Costs and Organizational Complexity}

In an increasingly dynamic market, it is essential to rapidly identify changes in the business environment and address consumer demand quickly and comprehensively. In such a competitive context, responsiveness has become a theme of utmost importance in the economic debate. It can be defined as a firm's ability to positively and timely respond to customer requests (Holweg, 2005). Slack (1991) postulated a close connection between the concepts of flexibility and responsiveness. He identified different types of flexibility and classified them in a hierarchical order: system flexibility, which can also be termed as responsiveness, is at the top of the pyramid and relies on operations' flexibility; this, in turn, is based on multiple factors, such as flexible labor. Holweg (2005) analyzed the relationship between flexibility and responsiveness in light of the existing literature and concluded that the former is more generic and can be interpreted as the ability to adapt to transformations affecting the external or internal environment, whereas the latter refers to an organization's capacity to promptly respond to customer demand. Both Slack (2001) and Holweg (2005) assumed that certain forms of flexibility are necessary to be responsive. Their assumption appears to be well-founded on the basis of some practical considerations: firms can quickly meet customer requests and thus be responsive, whether and to the degree to which they can rapidly adapt 
production volumes, types of products or services and delivery time to demand (Hasan et al., 2014). Achieving responsiveness requires firms to improve some internal aspects, such as inventory management and the use of labor force and technology. These interventions typically impact a company's organization and operational costs. For example, employing a more sophisticated technology and adjusting the production capacity to be more responsive may increase total operational costs (Ebrahim et al., 2014). SMEs display a higher degree of flexibility than large businesses. As a result, they can adapt to environmental changes within a shorter timeframe. Nevertheless, a limited availability of financial resources and other structural constraints affecting SMEs may be an obstacle to achieving or maintaining the desired level of responsiveness (Wang, 2016).

Such observations draw attention to the influence of costs on the internationalization of SMEs. These firms typically show lower levels of output and a less efficient production process compared to large businesses. As a result, they tend to be less competitive in terms of cost and face more difficulty in performing expensive activities, such as research and development and large-scale marketing communication. Hence, costs are a source of competitive disadvantage and a barrier to foreign market entry for SMEs (Rahman et al., 2019). An international venture may imply a wide range of additional expenses, such as those related to the recruitment of new managers and employees, the purchase of new facilities and equipment, the promotion of the company's products or services and the compliance with foreign laws and regulations. SMEs expanding internationally are also confronted with cultural differences, which may prevent them from acquiring or fully understanding important information about the selected market. The resulting knowledge gap may give rise to unexpected costs. Hence, various forms of cultural distance may hide some costs and hamper a firm's international expansion. Companies may face such knowledge barriers both after their market entry and at an earlier stage, when considering the possibility of approaching a new country (Perri et al., 2013). It is worth noting that SMEs evaluate internationalization costs not only based on objective data, but also through their own subjective perceptions. They tend to assess the cost of going global as high when they perceive that their international experience is too limited. Hence, there is a close connection between how SMEs see themselves, notably their experiential knowledge, and the way they perceive the costs related to international operations (Suh et al., 2008).

A process of international expansion entails changes which may significantly increase a firm's organizational complexity. There is no general agreement on the concept of organizational complexity in the literature. For example, Dooley (2002) defined it as the level of differentiation between the various elements forming an organization, while Luhmann (1995) observed that a set of intertwined elements can be viewed as complex when it is impossible to connect each component with every other component at any time. Given the controversial nature of the term, Van Gigch (1991) suggested the adoption of a tailored approach, considering the specificities of the issue under study. The present research relies on a two-faceted definition of organizational complexity: structural and process-oriented. The former refers to the number and diversity of the elements forming an organization and their interconnections, whereas the latter describes the number and diversity of process flows (Windt et al., 2008). Based on this interpretation, it can be argued that a firm becomes more complex when it introduces changes involving a higher number of employees or managers, a more sophisticated organizational structure, new and more articulated procedures or coordination mechanisms between different functional areas. Companies generally opt for more complex organizational solutions to respond to a growingly complex and challenging business environment (Dooley, 2002). A rapid and continuous evolution of technology, ever-rising levels of competition in all sectors and the development of interconnections between economic operators from different countries can be considered the main characteristics of such a multifaceted context (Surugiu and Surugiu, 2015). An increasing degree of organizational complexity can be clearly observed in manufacturing small and medium-sized enterprises expanding beyond their domestic borders. To compete in global markets more effectively, they revise, to greater or a lesser extent, their organization, through the adoption of more complex structures and processes (Nummela et al., 2006). 


\section{The Connection between International Business Expansion and Company Performance}

The connection existing between internationalization and company performance has been explored from different perspectives in the literature. The academic debate has particularly focused on two main aspects: how to measure a company's internationalization level and how to evaluate the impact of an international venture on firm performance (Lee et al., 2010).

To assess a firm's degree of internationalization, the so-called structural attribute is frequently employed in the literature (Sullivan, 1994). It refers to the resources that firms possess abroad and is measured in different ways, e.g. by estimating the ratio between foreign and total assets (Daniels and Bracker, 1989) or considering a company's number of foreign subsidiaries (Nguyen, 2016). Other common criteria helping to determine a company's internationalization level are attitudinal attribute and performance (Sullivan, 1994). The former can be defined as the international orientation of a firm's management and is often measured by considering top managers' years of experience in foreign markets (Nguyen, 2016). Performance can be practically assessed through a large variety of parameters, such as the ratio between foreign and total sales (Daniels and Bracker, 1989) or between foreign and total profits (Eppink and Van Rhijn, 1988). These studies allow to analyze a firm's international expansion from different standpoints. However, some of the proposed indicators seem to be suitable for large corporations rather than firms of any size. For example, considering the number of foreign subsidiaries to evaluate a firm's international presence does not fit small and medium-sized enterprises, which often opt for lower-commitment solutions due to their financial and organizational constraints.

Different models can be employed to determine how internationalization impacts company performance. A popular framework is the Positive Linear Model. It relies on the assumption that an international growth process has positive effects on company performance. In particular, as a firm enhances its international presence, its performance improves (Nachum, 2004). Conversely, the Negative Linear Model is based on the idea that internationalization negatively affects firm performance (Collins, 1990). The first model implies that firms expanding internationally can increase sales, diversify risk, achieve economies of scale and obtain other advantages improving their overall results (Hsu and Pereira, 2006). The studies proposing a negative linear relationship draw attention to the progressive cost increases related to international ventures (Geringer et al., 2000). The U-Shaped Model entails a non-linear connection between the two variables (Qian, 1997). More specifically, it emphasizes the idea that company performance declines during the first stages of an international growth process but, as the business gains experience, it improves. In the Inverted UShaped Model, the aforementioned phases occur in reverse order, because costs and organizational complexity are assumed to grow over time (Chao and Kumar, 2009). The U-shaped model stresses the importance of experience and market knowledge. It contends that a firm is not familiar with foreign markets at the beginning of its internationalization process and thus is confronted with a number of difficulties, exerting a negative influence on its performance.

A company gradually develops a deeper market knowledge and adjusts its organization to the foreign business environment. As a result, it can eventually achieve better results (Contractor et al., 2007). The S-Shaped model describes the reaction of firm performance to an internationalization process through three stages: a negative slope followed by a growth phase and a new decline. The initial decrease is justified by high operational costs, i.e. transportation and communication, and the firm's lack of familiarity with the new market. The subsequent growth stage stems from a more effective management of international operations. The third and last declining phase suggests that the advantages of going global have a certain lifespan (Lu and Beamish, 2004). Hence, this model relies on the assumption that internationalization entails high initial costs and the benefits stemming from an international expansion cannot last forever. In particular, during the first phase of an international growth process, firms need to make significant efforts from an organizational and economic standpoint to adapt to their target market and thus costs outweigh benefits (Ozdemir and Upneja, 2016). After such an adaptation stage, firms can make the most of their efforts and increase their profitability. The benefits arising from internationalization can reach a certain point and then inevitably decrease (Tallman and Li, 1996). 
It is worth noting that the aforementioned models describe the impact of internationalization on company performance in general terms and none of them specifically focuses on small and mediumsized enterprises. When developing an international expansion strategy, SMEs would need tailormade analytical tools supporting their decision-making process. A key aspect of international strategic planning is to determine if and how a firm can continue to benefit from its existing competitive advantages and, at the same time, search for new opportunities in other markets (Zhang et al., 2015).

\section{The Italian Fashion Industry: Overview and Role of SMEs}

Fashion holds a leading position in the Italian business landscape. It accounts for $1.3 \%$ of the national gross domestic product and has an annual gross revenue of $€ 70.4$ billion. Clothing is the largest sector in terms of revenue, followed by leather goods and glasses. The industry heavily depends on foreign markets, as over $60 \%$ of total sales are generated beyond the national boundaries, especially in the United States, China and Japan (Mediobanca 2020).

Advanced countries are mature markets, with limited changes in terms of economic and demographic development. Since consumption levels are high, even a moderate GDP growth may allow Italian fashion firms, particularly SMEs, to significantly expand their business. Emerging economies show a fast growth rate and thus represent an increasingly important destination for fashion products. However, international trade wars may negatively affect the performance of the Italian fashion industry. For instance, disputes about tariff and non-tariff barriers between the largest economies may reduce export levels, with detrimental effects on firms operating internationally. Counterfeiting is an additional reason for concern. Italian brands are among the most imitated at a global level, due to the quality and design of their products and Made in Italy's reputation. The manufacture and sale of counterfeited products cause Italian companies to lose market shares and thus experience severe financial losses (Confindustria, 2019). The Italian fashion industry encompasses world-renowned large corporations, such as Gucci, Prada and Ferragamo, and a wide number of SMEs. In this regard, it is worth noting that large companies generally outsource a significant portion of their production activities to smaller firms. Such a close collaboration between businesses of different size is considered to be one of the strengths of the Italian fashion system. However, not all SMEs work exclusively for third parties. Some of them produce and sell under their own brand name or have a hybrid approach, combining the two types of activity.

A key success factor of Italian fashion is the existence of various industry clusters. These refer to aggregations of companies based in the same territory, working in the same business sector and tightly connected with each other and local government bodies (Porter, 2000). The main fashion clusters are located in three Italian regions, namely Tuscany, Lombardy and Veneto. Clustered SMEs typically share human and technical resources, develop joint-activities and pursue common objectives (Kozyrev and Malyzhenkov, 2011). Most Italian SMEs, including those operating in the fashion industry, are family-owned and show a limited presence of outside managers. Hence, business owners and their family members tend to concentrate all or most managerial functions in their own hands. The dominant role of families is associated with cultural factors, notably with the lack of a clear dividing line between companies and their owners (Corbetta, 1985).

The Italian fashion SMEs focusing only on third-party activities have no direct access to foreign markets. However, fluctuations in foreign demand generally affects their operations, determining an increase or decrease in their production levels and profitability. Conversely, SMEs producing under their own brand name develop relationships with foreign interlocutors and have visibility in the marketplace. They adopt various market entry strategies, ranging from low-risk options, such as indirect exporting, to strategic alliances and foreign subsidiaries (Ahi et al., 2017). Regardless of the selected entry mode, they tend to participate in international trade fairs and exhibitions to network with current and potential customers and business partners. To compete both nationally and internationally, the majority of Italian SMEs operate in the high and mid-high market segments. Such a strategic positioning allows them to avoid the competition of firms from low-labor cost countries, namely developing and emerging economies, to have higher profit margins and to take advantage of their extensive expertise and creativity (Temperini et al., 2016). 


\section{Data Collection and Analysis}

\section{Research Methodology}

The present study relies on the explanatory sequential design, a form of mixed methods in which quantitative and qualitative research activities are performed in two consecutives phases. In this specific case, the researcher first collected quantitative data through a survey and subsequently conducted a set of semi-structured interviews. In the second phase, he performed a qualitative evaluation of the results emerging from the first stage and explained them more in-depth (Creswell and Creswell, 2014). The survey was performed to assess the relationship between each of the variables under study (organizational complexity, costs and responsiveness) and an international expansion process by five-point Likert-type scale questions.

The survey data were summarized through descriptive statistics, notably median, mean and frequency tables. To derive inferences from quantitative data, the logit and probit regression models were used, whereas the information provided by each participant through semi-structured interviews were examined and interpreted by means of a thematic analysis. This method can be considered in line with the purposes of the present study, as it is commonly used to analyze the ideas and opinions of different participants and to identify similarities and differences between them. Also, it provides a detailed explanation of qualitative data and entails a high degree of flexibility (Nowell et al., 2017).

\section{Sampling}

The survey targeted a group of 360 of Italian small and medium-sized enterprises operating in the global fashion industry. The interview sessions addressed 36 firms participating in the survey. The researcher selected all participant companies among the members of an Italian employers' association. For the purposes of the present study, he employed the notion of SME provided by the European Union. According to this, SMEs include firms fulfilling one of the following criteria: an annual turnover not exceeding $€ 50$ million and a number of employees not higher than 249 units (Karadag, 2015).

The participants were selected through the stratified convenience technique among SMEs from four fashion sectors, namely textile, clothing, leather accessories and footwear. The heterogeneous nature of the sample was considered necessary to reduce the possible influence of sector-specific factors on the research activities. Each firm participated in the project through one representative (owner/manager), possessing detailed information about the company's internationalization process. Each participant was required to respond to the researcher's questions based on his/her work experience and understanding. Upon completion of the research project, all the participants received a detailed report, showing how Italian fashion SMEs' exploitation activities change in response to an international growth process.

\section{Findings}

The present section presents the research findings in relation to each research question. Overall, 310 companies, accounting for $86 \%$ of the target sample, participated in the survey within the set deadline. The interview sessions involved 25 survey respondents. Hence, the interview response rate was $81 \%$.

RQ1: What is the impact of internationalization on SMEs' organizational complexity?

The large majority of the survey participants $(73 \%$ of the sample) observed a high or very high increase in the structural complexity of their firms as a result of an international expansion strategy. Almost the same percentage of respondents (74\%) declared that approaching new markets had major or severe effects on their companies in terms of business processes. A set of interviews clarified that internationalization confronted firms with the need to perform additional and more complex operations and thus led them to rethink their processes and to introduce more advanced organizational models. As a result of these reorganization efforts, most SMEs experienced disorientation, confusion and operational problems reducing their effectiveness in existing markets. 
RQ2: How are SMEs' costs related to an international expansion process?

Most entrepreneurs/managers participating in the survey (77\%) reported a strong or very strong impact of internationalization on their companies' fixed costs. A slightly larger portion of respondents (79\%) observed a rise in variable costs and ranked it as major or severe. During the interview sessions, it emerged that fixed costs mainly grew due to long-term investment, such as the creation of production plants overseas and the purchase of machinery, while the increase in variable costs was driven by a higher number of customers and a proportional change in terms of output. Most interviewees reported that such cost increases were not accompanied by a corresponding growth in revenue during the first stages of internationalization and thus exerted a negative influence on their firms' financial situation and ability to exploit existing markets.

RQ3: How does an international growth strategy influence SMEs' responsiveness?

Half of the survey participants stated that their ability to positively respond to customer requests moderately decreased due to internationalization. According to semi-structured interviews, some companies experienced such a decrease only during the initial phase of their internationalization process, because they were not ready to serve a wider customer base. A group of survey respondents, accounting for $40 \%$ of the sample, observed a high or severe impact of internationalization on this form of responsiveness, while the remaining portion of the surveyed companies $(10 \%)$ reported minor or no effects. In ranking the influence of internationalization on their ability to timely deliver products/services, $43 \%$ of the survey respondents reported moderate effects. Interviews clarified that such effects occurred at the early stages of firms' international expansion and stemmed from the complexity of international operations. Almost one third of the survey respondents (31\%) perceived a major or severe impact, while a smaller portion of the sample (26\%) observed no or minor effects. According to frequency data, small firms perceived a higher impact of internationalization on both forms of responsiveness compared to medium-sized enterprises. The logit and probit models confirmed the existence of a negative relationship between company size and perceived impact of internationalization on responsiveness.

\section{Concluding Remarks}

Several organizational constraints limit the Italian fashion SMEs' ability to develop a comprehensive understanding of the global business environment and to maintain the same level of competitiveness throughout their international expansion process. Approaching new markets allows these firms to seize new business opportunities and increase their profitability, but also confronts them with difficult challenges (Wang, 2016).

The early stages of internationalization typically result in rising net costs, a higher degree of organizational complexity and a lower level of responsiveness, with detrimental effects on SMEs' operations and performance. The progressive acquisition of experience and the introduction of organizational adjustments mitigate such a negative impact over time ( $\mathrm{Lu}$ and Beamish, 2001). Nevertheless, both the literature and the research findings show that it is preferable to adopt a proactive approach, allowing SMEs to prevent organizational problems related to internationalization processes (Lernoux, 2013). In this regard, it is essential to acquire a detailed market knowledge prior to expanding internationally (Contractor et al., 2007). It is equally important to engage in strategic planning, especially to firms which need to optimize the scarce resources at their disposal (George et al., 2019). These observations suggest the need for Italian fashion SMEs to rethink their approach to foreign markets. Although operating internationally is a necessity rather than a choice, it is crucial for business managers/owners to preliminarily evaluate some key aspects: how well they know the selected market; how accurately they have planned their entry; whether and to what degree a new international venture may have negative effects on exploitation activities and performance in the short and long term. Such a comprehensive evaluation can help SMEs set their priorities and allocate resources more effectively and efficiently. 
The present study has significant academic implications. On the one hand, it confirms the impact of internationalization on business performance described by the U-shaped model; on the other hand, it goes beyond this theoretical pattern. In particular, it explains, in operational terms, why and how SMEs may face difficulties at the early stages of their foreign expansion process. It emphasizes the idea that an international growth strategy may entail not only additional costs, but also a lower degree of responsiveness and a higher level of organizational complexity. Being aware of such possible consequences is of utmost importance both ex post, when evaluating the outcomes of international activities, and ex ante, during the strategic planning phase, to assess the feasibility and convenience of a market entry strategy. The research findings also make a contribution to the debate on the international ambidexterity of SMEs. They indicate that an increased awareness of the negative effects stemming from internationalization can help SMEs combine their exploitative and explorative tasks more effectively and thus improve their ability to overcome the challenges of the global market.

\section{Limitations and Recommendations}

To address the research questions, the present study employed a mixed approach, which allowed a group of Italian fashion SMEs to express their own perceptions about the difficulties stemming from an international expansion strategy. However, exploring the research problem only from SMEs' perspective may be viewed as a limitation. In addition, it may be argued that the sample not necessarily reflects the ideas and opinions of a much larger population and thus the project results cannot be widely generalized. Nevertheless, the research findings on the factors hampering SMEs' internationalization finds broad support across the strategic management literature (Stonkute and Vveinhardt, 2016; Wang, 2016).

Future studies might investigate the topic from a different standpoint, for example through a set of interviews to experts from the academic and consulting sectors. The contribution of such qualified professionals would offer a deeper understanding of the relationship between SMEs and internationalization in the context of the Italian fashion industry. Using expert interviews to develop a better knowledge and understanding of complex phenomena is widely accepted in social sciences (Bogner et al., 2009). The present project draws attention to major operational problems affecting Italian fashion SMEs during their foreign expansion process. Hence, the next logical step would be a study designed to ascertain how SMEs can overcome their difficulties. To this purpose, it might be useful to identify firms' best practices in terms of approach to foreign markets and to assess their generalizability. Based on the extant literature, learning from the best in class is not a frequent practice among SMEs, but it may significantly improve a firm's performance and thus justifies further research in this direction (Cassell et al., 2001). Also, it would be interesting to understand how Italian business associations, chambers of commerce and governmental institutions concretely support the international growth of fashion SMEs. The need to perform such research activities arises from participants' statements. For instance, an entrepreneur operating in the footwear industry asserted:

"I did not know how to reorganize my firm to timely serve an ever-growing number of customers in China. My business association assisted me in recruiting personnel, establishing cooperation with new suppliers and managing international logistics. The first year was extremely challenging, but my firm gradually regained momentum thanks to its reorganization process and the precious support provided by the local employers' association".

Acquiring a better knowledge of the interaction between the aforementioned organizations and fashion SMEs would help policy makers identify possible inefficiencies and thus develop more effective support strategies. 


\section{References}

Ahi, A., Baronchelli, G., Kuivalainen, O., \& Piantoni, M. (2017). International market entry: How do small and medium-sized enterprises make decisions?. Journal of International Marketing, 25(1), 1-21. doi: 10.1509/jim.15.0130.

Banham, H. (2010). External environmental analysis for small and medium enterprises (SMEs). Journal of Business \& Economics Research (JBER), 8(10), 19-25.

Bogner, A., Littig, B., \& Menz, W. (2009). Introduction: Expert interviews - an introduction to a new methodological debate. In: A. Bogner, B. Littig, \& W. Menz (Eds.), Interviewing Experts ( $1^{\text {st }}$ ed., pp.1-12). Palgrave Macmillan. doi.org/10.1057/9780230244276_1

Cassell, C., Nadin, S., \& Older Gray, M. (2001). The use and effectiveness of benchmarking in SMEs. Benchmarking: An International Journal, 8(3), 212-222. doi: 10.1108/eum0000000005624

Cerrato, D., \& Piva, M. (2010). The internationalization of small and medium-sized enterprises: The effect of family management, human capital and foreign ownership. Journal of Management \& Governance, 16(4), 617-644. doi.org/10.1007/s10997-010-9166-x

Chao, M., \& Kumar, V. (2009). The impact of institutional distance on the international diversityperformance relationship. SSRN Electronic Journal, 45(1), 93-103. doi: $10.2139 /$ ssrn. 1365094

Collins, J. (1990). A market performance comparison of U.S. firms active in domestic, developed and developing countries. Journal of International Business Studies, 21(2), 271-287. doi: $10.1057 /$ palgrave.jibs. 8490335

Confindustria. (2019). Esportare la dolce vita: Il potenziale dei beni finali di consumo belli e ben fatti sui mercati esteri, https://www.confindustria.it/home/centro-studi/temi-di- (Accessed 13 July 2020).

Contractor, F., Kumar, V., \& Kundu, S. (2007). Nature of the relationship between international expansion and performance: The case of emerging market firms. Journal of World Business, 42(4), 401-417. doi: 10.1016/j.jwb.2007.06.003

Corbetta, G. (1995). Patterns of development of family businesses in Italy. Family Business Review, 8(4), 255-265. doi: 10.1111/j.1741-6248.1995.00255.x

Creswell, J. W., \& Creswell, J.D. (2014). Research design: Qualitative, quantitative, and mixed methods approaches $\left(5^{\text {th }}\right.$ ed.). SAGE.

Daniels, J., \& Bracker, J. (1989). Profit performance: Do foreign operations make a difference?. Management International Review, 29(1), 46-56.

Dooley, K. (2002). Organizational complexity. In M. Warner (Ed.), International Encyclopedia of Business and Management (pp. 5013-5022). Thompson Learning.

Ebrahim, Z., Ahmad, N.A., \& Muhamad, M. R. (2014). Understanding responsiveness in manufacturing operations. Science International (Lahore), 26(5), 1663-1666.

Eppink, D., \& Van Rhijn, B. (1988). The internationalization of Dutch insurance companies. Long Range Planning, 21(5), 54-60. doi: 10.1016/0024-6301(88)90105-7

George, B., Walker, R., \& Monster, J. (2019). Does strategic planning improve organizational performance? A meta-analysis. Public Administration Review, 79(6), 810-819. doi: 10.1111/puar.13104

Geringer, J., Tallman, S., \& Olsen, D. (2000). Product and international diversification among Japanese multinational firms. Strategic Management Journal, 21(1), 51-80. doi: 10.1002/(sici)1097-0266(200001)21:1<51::aid-smj77>3.0.co;2-k

Holweg, M. (2005). The three dimensions of responsiveness. International Journal of Operations \& Production Management, 25(7), 603-622. doi: 10.1108/01443570510605063

Hsu, C., \& Pereira, A. (2008). Internationalization and performance: The moderating effects of organizational learning. Omega, 36(2), 188-205. doi: 10.1016/j.omega.2006.06.004

Huynh, H. T. N., Nguyen, P. V., \& Tran, K. T. (2018). Internationalization and performance of Vietnamese manufacturing firms: Does organizational slack matter? Administrative Sciences, 8(4), 1-15. 
Judge, W., \& Blocker, C. (2008). Organizational capacity for change and strategic ambidexterity. European Journal of Marketing, 42(9/10), 915-926. doi: 10.1108/03090560810891073

Karadag, H. (2015). The role and challenges of small and medium-sized enterprises (SMEs) in emerging economies: An analysis from Turkey. Business and Management Studies, 1(2), 179-188. doi: 10.11114/bms.v1i2.1049

Kozyrev, O., \& Malyzhenkov, P. (2011). Industrial clusters as the form of the territorial organization of economy in Russia and Italy. European Journal of Economics, Finance and Administrative Sciences, (42), 133-138.

Lavie, D., Stettner, U., \& Tushman, M. (2010). Exploration and exploitation within and across organizations. The Academy of Management Annals, 4(1), 109-155.

Lee, T., Chan, K., Yeh, J., \& Chan, H. (2010). The impact of internationalization on firm performance: A quantile regression analysis. International Review of Accounting, Banking and Finance, 2(4), 39-59.

Lernoux, F. (2013). Internationalisation of SMEs. De Boeck \& Larcier.

Lu, J., \& Beamish, P. (2001). The internationalization and performance of SMEs. Strategic Management Journal, 22(6-7), 565-586. doi: 10.1002/smj.184

$\mathrm{Lu}$, J., \& Beamish, P. (2004). International diversification and firm performance: The s-curve hypothesis. Academy of Management Journal, 47(4), 598-609. doi: 10.5465/20159604

Luhmann, N. (1995) Social Systems. Stanford University Press.

Mediobanca. (2020). Report on large Italian and European fashion companies, [www document] https://www.mbres.it/sites/default/files/resources/rs_Focus-Fashion-2019.pdf (accessed 30 July 2020).

Nachum, L. (2004). Geographic and industrial diversification of developing country firms. Journal of Management Studies, 41(2), 273-294. doi: 10.1111/j.1467-6486.2004.00432.x

Nguyen, Q. (2016). Multinationality and performance literature: A critical review and future research agenda. Management International Review, 57(3), 311-347. doi: 10.1007/s11575-016-0290y

Nowell, L., Norris, J., White, D., \& Moules, N. (2017). Thematic analysis: Striving to meet trustworthiness criteria. International Journal of Qualitative Methods, 16(1), 1-13. doi: $10.1177 / 1609406917733847$

Nummela, N., Loane, S., \& Bell, J. (2006). Change in SME internationalization: An Irish perspective. Journal of Small Business and Enterprise Development, 13(4), 562-583. doi: $10.1108 / 14626000610705750$

Ozdemir, O., \& Upneja, A. (2016). The role of internationalization on the IPO performance of service firms: Examination of initial returns, long-run returns, and survivability. International Business Review, 25(5), 997-1009. doi: 10.1016/j.ibusrev.2016.01.009

Perri, A., Checchinato, F., \& Colapinto, C. (2013). The hidden costs of going global: Insights from firms' entry into foreign markets (Working Paper No.26), [www document] https://iris.unive.it/handle/10278/39093\#.XamC-OgzaUk (accessed 15 June 2020).

Porter, M. (2000). Location, competition, and economic development: Local clusters in a global economy. Economic Development Quarterly, 14(1), 15-34. doi: $10.1177 / 089124240001400105$

Qian, G. (1997). Assessing product-market diversification of US firms. Management International Review, 37(2), 127-149.

Rahman, M., Akter, M., Odunukan, K., \& Haque, S. (2019). Examining economic and technology related barriers of small and medium sized enterprises internationalisation: An emerging economy context. Business Strategy \& Development, 3(1), 16-27. doi: 10.1002/bsd2.71

Slack, N. (1991). The manufacturing advantage. Mercury Books.

Stonkute, E., \& Vveinhardt, J. (2016). Key success factors for small and medium-sized enterprises in a context of global supply chains. In M. Bilgin, \& H. Danis (Eds.), Eurasian Studies in Business and Economics, 3(1), pp. 89-102). Springer. doi: 10.1007/978-3-319-27570-3_9 
Suh, T., Bae, M., \& Kundu, S. (2008). Smaller firms' perceived cost and attractiveness in international markets. Journal of Global Marketing, 21(1), 5-18. doi: 10.1300/j042v21n01_02

Sullivan, D. (1994). Measuring the degree of internationalization of a firm. Journal of International Business Studies, 25(2), 325-342. doi: 10.1057/palgrave.jibs.8490203

Surugiu, M., \& Surugiu, C. (2015). International trade, globalization and economic interdependence between European countries: Implications for businesses and marketing framework. Procedia Economics and Finance, 32, 131-138. doi: 10.1016/s22125671(15)01374-x

Tallman, S., \& Li, J. (1996). Effects of international diversity and product diversity on the performance of multinational firms. Academy of Management Journal, 39(1), 179-196. doi: $10.2307 / 256635$

Temperini, V., Gregori, G., \& Palanga, P. (2016). The brand Made in Italy: A critical analysis. Management Studies, 4(3), 93-103. doi: 10.17265/2328-2185/2016.03.001

Van Gigch, J. (1991). System design modeling and metamodeling. Plenum Press.

Wang, Y. (2016). What are the biggest obstacles to growth of SMEs in developing countries? - An empirical evidence from an enterprise survey. Borsa Istanbul Review, 16(3), 167-176. doi: 10.1016/j.bir.2016.06.001

Windt, K., Philipp, T., \& Böse, F. (2008). Complexity cube for the characterization of complex production systems. International Journal of Computer Integrated Manufacturing, 21(2), 195-200. doi: 10.1080/09511920701607725

Ye, J., Dong, B., \& Lee, J., (2017). The long-term impact of service empathy and responsiveness on customer satisfaction and profitability: A longitudinal investigation in a healthcare context. Marketing Letters, 28(4), 551-564.

Zhang, H., Wu, F., \& Cui, A. (2015). Balancing market exploration and market exploitation in product innovation: A contingency perspective. International Journal of Research in Marketing, 32(3), 297-308. doi: 10.1016/j.ijresmar.2015.03.004 